\title{
A simple model of inequality, occupational choice, and development
}

\author{
Maitreesh Ghatak $^{\mathrm{a}, *}$, Neville Nien-Huei Jiang ${ }^{\mathrm{b}}$ \\ ${ }^{a}$ Department of Economics, University of Chicago, Chicago, IL 60637, USA \\ ${ }^{\mathrm{b}}$ Department of Economics, Vanderbilt University, Nashville, TN 37235, USA
}

Received 1 February 2000; accepted 1 September 2001

\begin{abstract}
We analyze a simple and tractable model of occupational choice in the presence of credit market imperfections. We examine the effect of parameters governing technology and transaction costs, and history, in terms of the initial wealth distribution, in determining the long-term wealth distribution and the level of per capita income of an economy.
\end{abstract}

(C) 2002 Elsevier Science B.V. All rights reserved.

JEL classification: D31; D82; O10

Keywords: Wealth inequality; Occupational choice; Poverty traps

\section{Introduction}

A well-known implication of neoclassical growth theory is that economies that have similar preferences and technologies converge to the same steady state per capita income. ${ }^{1}$ In contrast, in development economics, we frequently encounter the idea of poverty traps: poor individuals and economies tend to remain poor because they start poor. One specific mechanism leading to the persistence of poverty that has recently received a lot of attention operates through borrowing constraints. ${ }^{2}$ Because threats of punishment work less well against the poor, they face greater borrowing constraints. This in turn prevents

\footnotetext{
* Corresponding author.

E-mail address: m-ghatak@uchicago.edu (M. Ghatak).

1 See Barro and Sala-i-Martin (1995).

2 See Galor and Zeira (1993), Banerjee and Newman (1993, 1994), Aghion and Bolton (1997), Piketty (1997), and Mookherjee and Ray (2000).
} 
them from adopting efficient technologies or choosing profitable occupations, and hence they remain poor. At the aggregate level, this implies that unlike in neoclassical growth models, two economies that are identical in terms of all parameters may end up with different levels of per capita incomes in the steady state if initially they have different distributions of wealth and hence different sizes of the class of credit rationed. This argument is often invoked to explain the evidence from cross-country analysis suggesting that various measures of initial inequality are negatively correlated with growth. ${ }^{3}$

However, it turns out that the dynamic behavior of an economy in the presence of credit market imperfections is fairly complicated, and even under strong simplifying assumptions regarding technology, preferences and market structure, it is difficult to give clear-cut answers to questions such as when do initial conditions matter, and if they do, what is the relationship between initial inequality and the steady-state level of per capita income of an economy. In this paper we try to answer these questions by analyzing a simple and tractable dynamic model of occupational choice in the presence of credit market imperfections.

Our paper is closely related to the important contributions of Galor and Zeira (1993) and Banerjee and Newman (1993). They provide the following insight: in the presence of credit market imperfections, the current distribution of wealth will determine the proportion of credit-constrained individuals in the economy, which in turn may affect equilibrium returns to various occupations in a way that affects the future wealth distribution through intergenerational transfers. As a result, the transition of the wealth distribution for the economy as a whole is nonlinear and hence the wealth distribution dynamics is quite complex. In particular, it is difficult to say much except for multiple stationary wealth distributions may exist, and that the initial distribution of wealth may determine which steady-state equilibrium the economy converges to. Banerjee and Newman (1993) offer some simple examples to show instances of hysteresis. However, even in these examples, it is not always the case that the greater is the size of the poor relative to that of the rich in the initial distribution, the lower will be the steady-state level of income.

We consider a simplified version of the model of Banerjee and Newman (1993). In particular, we have a simpler occupational structure. It turns out, as a result of this one needs no more information about the wealth distribution than the proportion of people whose wealth is below the level needed to start an enterprise. Even though general results in this class of nonlinear dynamic models of wealth distribution are hard to obtain as demonstrated by the Banerjee-Newman model, this simplification allows us to characterize precisely all the steady-state equilibria corresponding to various configurations of parameters governing technology, preferences and transactions costs. It also allows us to calculate the effect of changes in parameters of interest and the initial distribution of wealth on steady state per capita income. However, as a result of this simplification, we lose some of the richness of the Banerjee-Newman model, which allows for alternative institutional forms associated with the modern technology that differ in terms of agency costs.

\footnotetext{
3 See Benabou (1996) for a discussion of the empirical literature as well as other theoretical arguments consistent with the observed negative relationship between inequality and growth such as those based on political economy considerations.
} 
Some of our findings are as follows: first, whether hysteresis occurs depends on the size of the threshold level of wealth needed to start an enterprise relative to the productivity of the modern and the subsistence technologies. In particular, the larger is the productivity difference between the modern and subsistence technologies, the greater is the likelihood of multiple steady states. Second, for parameter values under which initial conditions matter, the greater is the fraction of the population who are initially poor, the lower is the steady-state income. Third, while some forms of technological progress can eliminate poverty traps, all kinds of technological improvements do not necessarily increase steadystate income. For example, an increase in the productivity of the small scale or subsistence sector that pushes up wages can act as a drag on the growth of the modern sector.

The plan of the paper is as follows. In Section 2 we analyze the basic model. In Section 3 we extend the basic model, which is nonstochastic, by allowing the saving rate to be subject to random shocks. In Section 4 we make some concluding remarks and Appendix A contains some technical proofs.

\section{The model}

\subsection{Demographics and preferences}

Consider an economy inhabited by infinitely lived dynasties represented by successive generations of agents who live for one period. The population is large and its size is normalized to 1 . There is no population growth. There are two goods in the economy, labor, and some final output which can serve both as a consumption good and a capital good. In period $t$ a dynasty $i$ is endowed with 1 unit of labor and an initial wealth $a_{i, t}$. It earns income by supplying labor and capital and the resulting income $y_{i, t}$ is divided at the end of the period between consumption $c_{i, t}$ and savings, or bequest to the next generation, $b_{i, t}$. Therefore,

$$
a_{i, t+1}=b_{i, t} .
$$

Following the literature, we assume that individuals have identical Cobb-Douglas utility functions over consumption and bequests, with $U^{i}\left(c_{i, t}, b_{i, t}\right)=c_{i, t}^{1-s} b_{i, t}^{s}$, where $s \in(0,1)$ and the budget constraint is $y_{i, t}=c_{i, t}+b_{i, t}$. This means that the current generation saves a constant fraction $s$ of its income and leaves it as bequest:

$$
a_{i, t+1}=s y_{i, t} .
$$

We also assume that all agents are risk-neutral.

In period $t$, wealth is distributed according to the probability measure $\lambda_{t}(\cdot)$, and for convenience, we define

$$
G_{t}(a) \equiv \lambda_{t}((-\infty, a)) .
$$

The function $G_{t}$ is very similar to the distribution function except that it does not include the measure at point $a$. 


\subsection{Production technologies}

There are two production technologies both of which are deterministic. One uses no capital and one unit of labor to produce $\underline{w}$ units of output. This will be described as a subsistence (or agricultural) technology. The other uses $I>0$ units of capital and two units of labor (one unit of supervisory labor and one unit of ordinary labor) to produce $q$ units of output. One supervisor (or entrepreneur) can perfectly monitor one worker spending her entire labor endowment. This will be described as an entrepreneurial (or industrial) technology. 4

Assumption 1. We assume that this technology is superior in the sense that the net output of using this technology is greater than were two units of labor using the subsistence technology. That is,

$$
q-r I>2 \underline{w}
$$

where $r(\geq 1)$ is the exogenously given gross interest rate. ${ }^{5}$

\subsection{Occupations}

There are three possible occupations open to an individual who has inherited wealth $a_{i, t}$ :

(a) Subsistence: The agent earns some income by using her labor endowment to produce $\underline{w}$ with the subsistence technology. She puts her inherited wealth in the bank, which yields $r a_{i, t}$. Therefore, her income is

$$
y_{i, t}^{\mathrm{S}}=\underline{w}+r a_{i, t}
$$

(b) Worker: The agent works for an entrepreneur for wage income $w_{t}$ (which is determined endogenously). She puts her inherited wealth in the bank, which yields $r a_{i, t}$. Therefore, her income is

$$
y_{i, t}^{\mathrm{W}}=w_{t}+r a_{i, t}
$$

(c) Entrepreneur: The agent invests an amount $I$ to start a firm and hires one worker to produce an output $q$ with certainty. Her job is to monitor the worker. The agent's income as an entrepreneur is the output of the project less wage and capital costs:

$$
y_{i, t}^{\mathrm{E}}=q-w_{t}+r\left(a_{i, t}-I\right) .
$$

\footnotetext{
4 In contrast in the Banerjee and Newman (1993) model, apart from these two types of technologies, there is a third one which involves some capital and one unit of labor ("self-employment").

5 We can think of the credit market as an international market where the given economy is 'small'.
} 


\subsection{Credit and labor markets}

The credit market is subject to transactions costs on the lending side due to imperfect enforcement of loan contracts. ${ }^{6}$ This results in credit rationing of the following form: if an individual's wealth is below a certain minimum level, she would not get a loan no matter how high the interest rate she offers. Following Banerjee and Newman (1993), a simple way to generate this form of credit rationing is as follows: a borrower may default on her loan (namely, $r(I-a)$ ), but the cost of this action is that she gets caught with some probability $\pi$ and then has to pay a fixed nonmonetary cost of $F$ due to imprisonment or social sanctions. Thus, only those individuals get loans whose wealth satisfies the incentive compatibility constraint (ICC) ${ }^{7}$ :

$$
\begin{aligned}
& \left(q-w_{t}\right)-r\left(I-a_{i, t}\right) \geq q-w_{t}-\pi F \\
& \text { or, } a_{i, t} \geq I-\frac{\pi F}{r} .
\end{aligned}
$$

The lower is an individual's wealth, the greater is her incentive to default because she has to borrow a greater amount to start an enterprise, and the level of sanctions against default is the same for all borrowers. Hence, only those who have a certain minimum amount of wealth (namely, $I-\pi F / r$ ) can borrow. ${ }^{8}$ Without loss of generality, we set $\pi=0$ so that only those who have enough wealth to fully finance their own enterprises are able to become entrepreneurs.

The wage rate at which entrepreneurs are indifferent between working as wage laborers and hiring workers is given by:

$$
\begin{aligned}
& q-\bar{w}+r\left(a_{i, t}-I\right)=\bar{w}+r a_{i, t} \\
& \text { or, } \bar{w}=\frac{q-r I}{2} .
\end{aligned}
$$

By Assumption 1, $\underline{w}<\bar{w}$. Below we show that to ensure labor market equilibrium, the wage rate $w$ must lie in the interval $[\underline{w}, \bar{w}]$. Hence, the occupation of entrepreneurship earns no less than any other occupation for all wages (and strictly so for all $w<\bar{w}$ ). Given the features of the credit market, only those individuals who own enough capital $(a \geq I)$ can become entrepreneurs even though everybody else would like to do so. We are going to

\footnotetext{
6 We are assuming there are no imperfections on the deposit side of the credit market: there is a constant rate of return of $r$ irrespective of the amount deposited.

7 It is being assumed that even if a borrower gets caught trying to avoid repaying her debt, she gets to consume her profits.

8 An implication of this form of credit rationing is that the threshold wealth level does not depend on the wage rate. Otherwise, the threshold wealth level will change with the wage rate. This tends to complicate the dynamics somewhat, but the basic results are not affected.
} 
refer to those individuals whose wealth is less than $I$ as capital-constrained, or simply, poor, and the rest as unconstrained, or rich.

The ICC tells us what fraction of the population is capital-constrained, namely, $G_{t}(I)$. Notice that this follows from our assumption that all entrepreneurs are self-financed and the credit market does not operate as $\pi=0$. Otherwise, the relevant fraction of the population that is capital-constrained would be $G_{t}(I-\pi F / r)$.

For $w_{t}<\underline{w}$, labor supply is zero, but for $w_{t}=\underline{w}$ labor supply jumps to $G_{t}(I)$ and as $w_{t}$ goes above $\underline{w}$, the supply of labor grows until the wage rate is high enough, namely, $\bar{w}$, such that entrepreneurs are indifferent between working as wage laborers and hiring workers. Now we are ready to write down the supply curve of labor:

$$
\begin{aligned}
& 0 \text { if } w_{t}<\underline{w} \\
& {\left[0, G_{t}(I)\right] \text { if } w_{t}=\underline{w}} \\
& G_{t}(I) \text { if } w_{t} \in(\underline{w}, \bar{w}) \\
& {\left[G_{t}(I), 1\right] \text { if } w_{t}=\bar{w}} \\
& 1 \text { if } w_{t}>\bar{w} .
\end{aligned}
$$

Conversely, to derive the demand curve for labor, we notice that for $w_{t}>\bar{w}$ there is no demand for labor; as $w_{t}$ falls to $\bar{w}$, the demand for labor jumps to any value between 0 and $1-G_{t}(I)$. When $w_{t}<\bar{w}$, the demand for labor is at a maximum, $1-G_{t}(I)$ and continues to remain so. Therefore, the demand for labor is:

$$
\begin{aligned}
& 0 \text { if } w_{t}>\bar{w} \\
& {\left[0,1-G_{t}(I)\right] \text { if } w_{t}=\bar{w}} \\
& 1-G_{t}(I) \text { if } w_{t}<\bar{w} .
\end{aligned}
$$

From the labor demand and supply schedules we can easily find the equilibrium wage rate in period $t$ :

$$
\begin{gathered}
\bar{w} \text { if } G_{t}(I)<\frac{1}{2} \\
w_{t}^{*}=[\underline{w}, \bar{w}] \text { if } G_{t}(I)=\frac{1}{2} \\
\underline{w} \text { if } G_{t}(I)>\frac{1}{2} .
\end{gathered}
$$

Since each entrepreneur hires exactly one worker, if there are more people who are capital-constrained (unconstrained), then the competition for entrepreneurs (workers) 
among them will drive the equilibrium wage rate down (up) to its lower (upper) bound. When $G_{t}(I)=1 / 2$, the equilibrium wage rate is indeterminate, and throughout this paper, we are going to assume that the wage rate is equal to $\bar{w}$ in this case.

Notice that on one hand, the equilibrium wage rate depends on the current wealth distribution but on the other hand, it also influences next period's wealth distribution through the savings behavior of currently active agents.

\subsection{Dynamics of individual wealth}

Consider the factors governing dynasty $i$ 's bequest. First of all, the initial wealth level of an agent determines her capital income and her occupational choice. Secondly, the current wage rate is determined by the economy-wide wealth distribution. With the knowledge of an individual's occupational choice and that the wage rate can take only two values $(\underline{w}$ and $\bar{w})$, we can write down the difference equations describing the evolution of a dynasty $i$ 's wealth as:

$$
\begin{aligned}
a_{i, t+1}\left(a_{i, t} \mid w_{t}=\underline{w}\right) & =s\left[r a_{i, t}+\underline{w}\right] & & \text { if } a_{i, t}<I \\
& =s\left[r\left(a_{i, t}-I\right)+q-\underline{w}\right] & & \text { if } a_{i, t} \geq I \\
a_{i, t+1}\left(a_{i, t} \mid w_{t}=\bar{w}\right) & =s\left[r a_{i, t}+\bar{w}\right] & & \forall a_{i, t} .
\end{aligned}
$$

Fig. 1 shows what these difference equations look like. Notice that there are two regimes of wealth transitions corresponding to the two wage levels. When the wage rate is low, an agent who is capital-constrained can only choose between being a worker and engaging in subsistence and in either case, her labor income is $\underline{w}$. A fraction $s$ of the sum of her labor income and her capital income $r a_{i, t}$ is left for her next generation. An agent who is not credit-constrained will strictly prefer to be an entrepreneur and her total income will be $r\left(a_{i, t}-I\right)+q-\underline{w}$. When the wage rate is high, nobody will engage in subsistence and all agents will be indifferent between being entrepreneurs and workers.

(a)

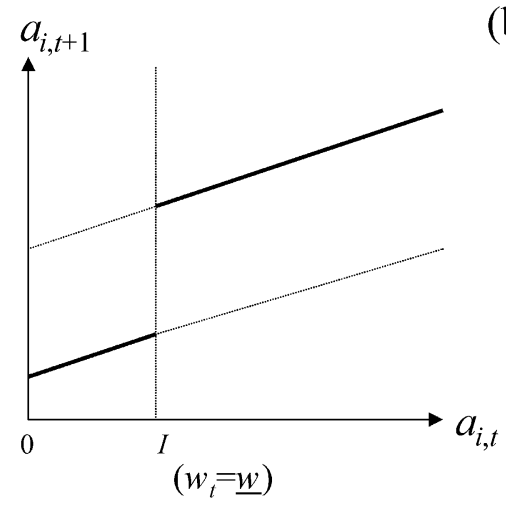

(b)

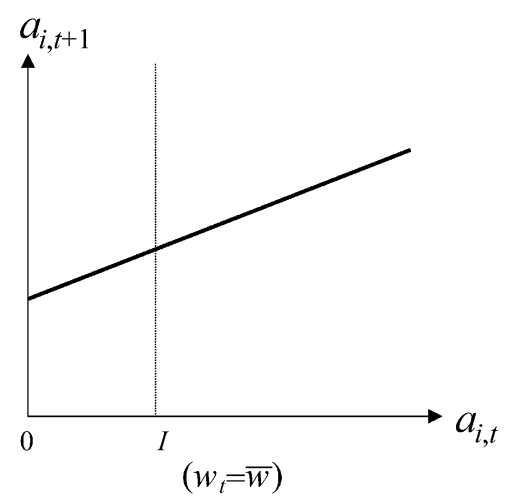

Fig. 1. Dynasty $i$ 's wealth transitions under different wage regimes. 
Assumption 2. We assume that it is not possible for a dynasty to get arbitrarily rich over time merely by saving a constant fraction of its income every period and earning interest on it:

$$
s r<1
$$

Assumptions 1 and 2 will be retained throughout this section.

\subsection{Stationary wealth distributions and wages}

In this section, we examine the long-run behavior of this economy. If the difference equations governing the wealth transitions are stable, it would be easy to prove the existence of a stationary wealth distribution. However, the fact that these difference equations depend on the wage levels raises the possibility that the process may not be stable. In particular, the concern here is that the wage rate may change infinitely often. The following lemma rules out this possibility.

\section{Lemma 1. The wage rate can change at most once.}

Proof: Notice that the difference equations are order-preserving. That is, $a_{i, t+1}>a_{j, t+1}$ if and only if $a_{i, t}>a_{j, t}$. Therefore, in order to study the wage dynamics, we can only look at the wealth dynamics of the dynasty which has the median wealth. Define $a_{t}^{m} \equiv \max \{a$ : $\left.G_{t}(a) \leq 1 / 2\right\}$. Note that $a_{t}^{m}$ is well defined because $G(\cdot)$ is continuous from below according to our definition. Then $a_{t}^{m} \geq I \Leftrightarrow G_{t}(I) \leq \frac{1}{2}$ which implies $w_{t}=\bar{w}$. Similarly, $a_{t}^{m}<I \Leftrightarrow G_{t}(I)$ $>\frac{1}{2}$ which implies $w_{t}=\underline{w}$. Now if $w_{t}=\underline{w}$ and $w_{t+1}=\bar{w}$, then we must have $a_{t}^{m}<I$ and $a_{t+1}^{m} \geq I$. This implies $s\left(r a_{t}^{m}+\underline{w}\right) \geq I \Rightarrow s \underline{w} \geq(1-s r) I \Rightarrow s(r a+w) \geq I$ for all $a \geq I$ and $w \in\{\underline{w}, \bar{w}\}$. That is, once the high-wage rate is reached, there will not be any downward mobility and hence the high wage will prevail forever. If $w_{t}=\bar{w}$ and $w_{t+1}=\underline{w}$, then we must have $a_{t}^{m} \geq I$ and $a_{t+1}^{m}<I$. This implies $s\left(r a_{t}^{m}+\bar{w}\right)<I \Rightarrow s \bar{w}<(1-s r) \stackrel{\Longrightarrow}{\Rightarrow}_{s}(r a+w)<I$ for all $a<I$ and $w \in\{\underline{w}, \bar{w}\}$. That is, there will not be any upward mobility and once the low-wage rate is reached, it will prevail forever. Therefore, we can conclude that starting with any initial distribution of wealth, the wage rate can change at most once.

Lemma 1 shows that the wage rate is constant in the long run and rules out the possibility of cycles or chaotic wage dynamics. Once the wage rate switches from low to high, there will be no downward mobility and so the high wage prevails forever and similarly, once the wage rate switches from high to low, there will be no upward mobility and the low-wage prevails forever. As a result, although we have two regimes of the wealth transition process, there will not be infinite switches from one to the other. Only one of them will prevail in the long run. However, for the same parameter values, both wealth transition processes could be candidates for the long-run equilibrium and which one is arrived at could depend on initial conditions. Together with Assumption 2, which implies there exists a stationary point for each difference equation, we immediately have:

Proposition 1: Given any initial wealth distribution, there exists a unique stationary wealth distribution to which it converges.

By Lemma 1 in the long run the wage rate is constant and corresponding to this wage rate, one of the two possible wealth transition processes will prevail. The difference equations associated with these processes have unique stationary points and so the wealth 
distribution of the economy will converge to a stationary distribution. This stationary wealth distribution will have all mass concentrated on one point (for the high-wage equilibrium) or two points (for the low-wage equilibrium) which is a consequence of the model being nonstochastic. Notice that the Lemma 1 and Proposition 1 do not suggest that given the parameters of the model there is a unique long-run wage rate, and a corresponding long-run stationary wealth distribution. Indeed, one of our main goals is to characterize parameter conditions under which multiple long-run equilibria could exist and to show which equilibrium the economy converges to depends on initial conditions. What these results do is to rule out cycles or chaotic behavior. Now we proceed to characterize how the long-run equilibrium of the economy depends on various parameters and the initial wealth distribution.

Let $a^{J}(w)$ be the stationary point of the difference equation describing the wealth transition of a dynasty engaged in occupation $J$ (where $J=\mathrm{S}, \mathrm{W}, \mathrm{E}$ denotes the three occupations: subsistence, worker, and entrepreneur) when the wage rate is $w$. Then we have

$$
\begin{aligned}
& a^{\mathrm{S}}(w)=\frac{s \underline{w}}{1-s r} \text { for all } w . \\
& a^{\mathrm{W}}(\underline{w})=\frac{s \underline{w}}{1-s r} \\
& a^{\mathrm{E}}(\underline{w})=\frac{s(q-r I-\underline{w})}{1-s r} \\
& a^{\mathrm{W}}(\bar{w})=a^{\mathrm{E}}(\bar{w})=\frac{s(q-r I)}{2(1-s r)} .
\end{aligned}
$$

By Assumption 1, $a^{\mathrm{E}}(\underline{w})>a^{\mathrm{E}}(\bar{w})=a^{\mathrm{W}}(\bar{w})>a^{\mathrm{W}}(\underline{w})$.

Comparing the values of these threshold levels of wealth with $I$, we can completely characterize the long-run outcome (in terms of the stationary distribution of wealth, the equilibrium wage rate and the level of net output) of the economy.

Proposition 2: The initial distribution of wealth matters in determining the stationary distribution of wealth and the long run equilibrium wage rate if and only if

$$
s(q-\underline{w}) \geq I>\frac{s \underline{w}}{1-s r} .
$$

Otherwise the economy converges to a high-wage equilibrium (if $I \leq s \underline{w} /(1-s r)$ ) or a subsistence equilibrium (if $I>s(q-\underline{w})$ ) irrespective of initial conditions.

Proof: The proof consists of the following two steps

Step 1. The following four cases characterize the steady-state equilibrium of the economy corresponding to various parameter values:

Case 1. $I>s(q-\underline{w}) \Leftrightarrow I>a^{\mathrm{E}}(\underline{w})$. This is a situation where the steady-state wealth of the entrepreneurial class cannot finance the operation of the industrial technology even 
when wages are as low as possible. The only equilibrium in this economy is therefore one where everyone is engaged in subsistence production irrespective of the initial wealth distribution $G_{0}$. As a result the stationary wealth distribution displays no inequality.

Case 2. $s(q-\underline{w}) \geq I>s q /(2-s r) \Leftrightarrow a^{\mathrm{E}}(\underline{w}) \geq I>a^{\mathrm{E}}(\bar{w})=a^{\mathrm{W}}(\bar{w})>a^{\mathrm{W}}(\underline{w})$. The condition that $a^{\mathrm{E}}(\underline{w}) \geq I$ implies $s[r(a-I)+q-\underline{w}] \geq I \forall a \geq I$. It says when the wage rate is low, offspring of individuals who are able to start an enterprise in the current period will also be able to do so in the next period, i.e., there is no downward mobility. Similarly, $I>a^{\mathrm{W}}(\underline{w})$ implies $s(r a+\underline{w})<I \forall a<I$, which means there is no upward mobility when the wage is low. If the economy starts out with the low-wage rate $\left(G_{0}(I)>1 / 2\right)$, there will not be any mobility in either direction. This implies that the wage rate will always be equal to $w$; the wealth of those dynasties that are initially capital-constrained will converge to $a^{\mathrm{W}}(\underline{\bar{w}})$; the wealth of those that are not will converge to $a^{\mathrm{E}}(\underline{w})$; and there will be $1-G_{0}(I)$ firms operating in each period. Now suppose the economy starts out with the high-wage rate $\left(G_{0}(I) \leq 1 / 2\right)$. The condition, $I>a^{\mathrm{E}}(\bar{w})=a^{\mathrm{W}}(\bar{w})$, implies $\bar{w}$ is not sustainable. There exists a finite $\tau$ such that $w_{\tau}=\bar{w}$ and $w_{\tau+1}=\underline{w}$. Thereafter the story is the same as above if we take $G_{\tau+1}(\cdot)$ as the initial wealth distribution in the new low-wage regime. And of course, $G_{\tau+1}$ depends on $G_{0}$.

Case 3. $s q /(2-s r) \geq I>s \underline{w} /(1-s r) \Leftrightarrow a^{\mathrm{E}}(\underline{w})>a^{\mathrm{E}}(\bar{w})=a^{\mathrm{W}}(\bar{w}) \geq I>a^{\mathrm{W}}(\underline{w})$. Again, since $a^{\mathrm{E}}(\underline{w})>I>a^{\mathrm{W}}(\underline{w})$, there is no upward or downward mobility when wage rate is low. Therefore, if the economy starts out at low-wage rate $\left(G_{0}(I)>1 / 2\right)$, the story is the same as in Case 2. However, the condition, $a^{\mathrm{E}}(\bar{w})=a^{\mathrm{W}}(\bar{w}) \geq I$, implies $s(r a+((q-r I) / 2)) \geq I \forall a \geq I$. Hence, when the wage rate is high, people who are not capital-constrained will remain unconstrained, i.e., there is no downward mobility. Therefore, if the economy starts out with $G_{0}(I) \leq 1 / 2$, the high wage $\bar{w}$ will last forever. As a result, every dynasty's wealth will converge to $a^{\mathrm{E}}(\bar{w})$.

Case 4. $s \underline{w} /(1-s r) \geq I \Leftrightarrow a^{\mathrm{W}}(\underline{w}) \geq I$. The high-wage equilibrium will result irrespective of $G_{0}$ because even when wages are low, the steady-state wealth level of the working class permits them to start a firm. As a result, the unique stationary wealth distribution displays no inequality.

Step 2. Next we show that the sets of parameter values that correspond to the four cases analyzed above are mutually exclusive and exhaustive with respect to the set of all admissible parameter values (i.e., those satisfying Assumptions 1 and 2).

Suppose $s \underline{w} /(1-s r) \leq I$. This inequality implies $[(2-s r) /(1-s r)] \underline{w} \leq 2 \underline{w}+I r$. As a result, Assumption $\overline{1}$, which guarantees $q>2 \underline{w}+I r$, also implies $q>[(2-s r) /(1-s r)] \underline{w}$, i.e., $q /$ $(2-s r)>\underline{w} /(1-s r)$. The last inequality in turn implies, upon rearranging, $s(\bar{q}-\underline{w})>s q /$ $(2-s r)$ and $s q /(2-s r)>s \underline{w} /(1-s r)$. Thus, we have the following inequality which is derived from Assumptions 1 and 2:

$$
s(q-\underline{w})>\frac{s q}{2-s r}>\frac{s \underline{w}}{1-s r}
$$

which holds so long as $s \underline{w} /(1-s r) \leq I$. If instead, $I<s \underline{w} /(1-s r)$, then Case 4 always applies. That is, the only possible equilibrium is the high-wage equilibrium.

Fig. 2 summarizes the four cases. Proposition 2 has several interesting economic implications which we discuss below. 


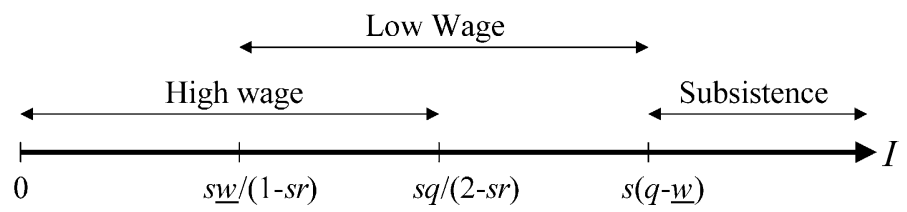

Fig. 2. Long-run wage rates under different parameter configurations (Non-Stochastic Model).

If there were no frictions in the credit market, so long as the modern technology is more productive than the subsistence technology (which is ensured by Assumption 1), it will be used by the entire economy. The initial distribution of wealth, the productivity of the subsistence technology or the propensity to save would not be relevant in determining total output. If credit markets are imperfect, Proposition 2 shows that the long-run equilibrium of the economy cannot be predicted by a simple comparison of the productivity of the two technologies. If the size of the wealth threshold needed to start an enterprise $(I)$ is very high, then the economy will collapse to subsistence sector since the steady-state wealth level of even a rich dynasty in a low-wage equilibrium will fall short of it. Conversely, if $I$ is very low, then the steady-state wealth level of even a poor dynasty in a low-wage equilibrium will exceed it. In this case, in the long run the economy will converge to a high-wage equilibrium where the whole population is engaged in the modern sector. For intermediate values of $I$, the long-run equilibrium of the economy cannot be predicted from the parameters governing technology and preferences only. The initial wealth distribution also matters. If the parameters are such that the low-wage equilibrium is the unique long-run equilibrium (i.e., this is the case where the steady-state wealth level of a dynasty under the high-wage equilibrium is less than $I$ ), the number of firms using the modern technology in the long-run equilibrium is the same as those at $t=0$ and this is how the initial wealth distribution matters. More interestingly, if the parameters are such that both the low and high-wage equilibrium are possible, then the initial distribution of wealth also determines which equilibrium will be chosen. If initially there are many dynasties who have wealth higher than $I$, then the highwage equilibrium will result, and this will enable others to accumulate enough wealth so that in the long run everyone can become an entrepreneur. If on the other hand, if initially the credit-constrained dynasties are in a majority, they will push the wage down in the labor market which will continue to keep them poor in successive generations.

Proposition 2 also suggests that the effect of changes in parameter values regarding technology and preferences may depend on the initial wealth distribution, and in particular, can push the economy from one type of steady-state equilibrium to another. Let us consider the effects of changes in various parameters of the model.

An increase in the productivity of the modern technology $q$ (as a result of technological change or economic policies, such as liberalizing the economy) will increase the income generated by existing enterprises using the modern technology. The effect of this on per capita income will depend on the initial wealth distribution under the low-wage equilibrium as that determines the number of firms using the modern technology, but not in the high-wage equilibrium. Moreover, if as a result of an increase in $q$ the steadystate wealth level of some individuals are pushed above $I$, the number of enterprises using the modern technology in a steady-state equilibrium may increase. This will be the case if 
initially $[s /(2-s r)] q<I$, and after the change $[s /(2-s r)] q \geq I$ (i.e., starting with a low-wage or a subsistence equilibrium, the high-wage equilibrium becomes feasible) or if initially $s(q-\underline{w})<I$, and after the change $s(q-\underline{w}) \geq I$ (i.e., starting with a subsistence equilibrium, the low-wage equilibrium becomes feasible). This is an instance where technological change can eliminate a poverty trap without any redistributive measures.

An increase in the productivity of the subsistence technology $\underline{w}$ (as a result of technological change, or government policies such as minimum wage laws or subsidy to small-scale industry) will increase per capita income by raising the incomes of those engaged in the subsistence sector. ${ }^{9}$ However, while an increase in $\underline{w}$ increases the steadystate wealth level of workers and those engaged in subsistence, it reduces the steady-state wealth level of entrepreneurs in a low-wage equilibrium. As a result, the effect of it on steady state income is ambiguous. For example, starting with a situation where $s(q-\underline{w}) \geq I$ (so that the low-wage equilibrium exists), an increase in $\underline{w}$ can lead to $s(q-\underline{w})<I$ and, as a result, the economy can converge to a subsistence equilibrium. On the other hand, suppose initially $s \underline{w} /(1-s r)<I$ (i.e., the steady-state wealth level of workers or those engaged in subsistence is less than $I$ ) and the economy is in a low-wage equilibrium. If after the change $s \underline{w} /(1-s r) \geq I$, the economy will converge to a high-wage equilibrium instead of a low-wage equilibrium. This exercise suggests that an increase in the productivity of a technology does not necessarily raise steady state per capita income. Indeed, an increase in the productivity of the small-scale or subsistence sector that pushes up wages can act as a drag on the growth of the modern sector by reducing the steady-state income of entrepreneurs.

The effect of an increase in $s$ is straightforward. It does not raise steady-state income directly in this model, but raises the steady-state wealth level of every dynasty. If an increase in $s$ pushes the steady-state wealth level of some individuals above $I$, the number of enterprises using the modern technology in a steady-state equilibrium will increase.

Previously, we have assumed that the chance of being caught from default is zero $(\pi=0)$. Therefore, there is actually no credit market in this economy-one needs to own the whole amount of capital required $(I)$ to start up a modern firm. Now suppose $\pi>0$, so that only $(I-(\pi F / r))$ is needed to become an entrepreneur. Other things being equal, since it is easier to reach this threshold, the economy is more likely to end up with a high-wage equilibrium. For the same reason, an increase in the punishment $(F)$ would have the same effect. Changes in the interest rate $(r)$, however, have two opposite effects. A decrease in $r$ would reduce the wealth threshold for borrowing on one hand, but on the other hand, it becomes harder to accumulate one's wealth. This suggests that improving the enforcement technology (i.e., increases in $\pi$ and $F$ ) has an unambiguously positive role in eliminating poverty traps, whereas the effect of lower capital scarcity in the international credit market (i.e., a decrease in $r$ ) has an ambiguous effect.

Let us define the total income of the economy, the sum of wage and profit income, as:

$$
Y=G(I) w+\{1-G(I)\}(q-w-I r)
$$

The following result compares the equilibria in terms of total income.

\footnotetext{
${ }^{9}$ It will also increase the wages of workers engaged in the modern sector. But this will be matched by a decrease in the profits of entrepreneurs and there will be no effect on per capita income.
} 
Proposition 3: For parameter values for which initial conditions matter, the greater is the fraction of the population who are initially poor, the lower is steady-state income.

Proof: Under a subsistence equilibrium, total income is $Y=\underline{w}$. In a low-wage equilibrium, total income is $Y=(q-I r)\{1-G(I)\}-\{1-2 G(I)\} \underline{w}$. Finally, in a high-wage equilibrium, total income is $Y=(q-I r) / 2$. Since $q-I r>\underline{w}$ by Assumption 2, and under a low-wage equilibrium $G(I) \geq 1 / 2$

$$
\frac{q-I r}{2} \geq(q-I r)\{1-G(I)\}-\{1-2 G(I)\} \underline{w}>\underline{w} .
$$

Hence, the total income of the economy under a high-wage equilibrium exceeds that under a low-wage equilibrium, which in turn exceeds that under a subsistence equilibrium. Proposition 2 shows that for the parameter values $s(q-\underline{w}) \geq I \geq s \underline{w} /(1-s r)$ (corresponding to Cases 2 and 3 ), if $G_{0}(I)>1 / 2$, then the economy converges to a low-wage equilibrium where only $1-G_{0}(I)$ firms operate. Hence, the proposition follows.

What this result shows is that even if the low-wage equilibrium is the unique equilibrium, the gain from having one less credit-constrained person is one more firm that uses the modern technology and generates greater income. When multiple equilibria exist, the long run gains from having a smaller number of people who are creditconstrained are much greater than in the previous case, since this might unleash market forces that push the economy to a high-wage equilibrium where the whole population is engaged in the modern sector.

The above result also shows that to the extent greater equality of the distribution of wealth reduces the fraction of the population who are capital-constrained, both greater equity and greater efficiency (in terms of total income) are achieved. As a result, one-shot redistributive policies can raise the total income of the economy permanently for parameter values for which the initial wealth distribution matters for the long-term performance of the economy, as Banerjee and Newman (1993) point out. To see this assume that the policy is implemented after the economy has settled down in a steady-state equilibrium. Suppose the government taxes bequests of rich dynasties and redistributes the revenue (so that the government budget is balanced) to poorer dynasties whose wealth is less than $I$ with the goal of making as many individuals to be able to start their own enterprises as possible. Naturally, this policy will have no effect when the economy is in a high-wage or subsistence equilibrium because everyone has equal wealth to start with. For the case of low-wage equilibrium, it can have an effect. Consider Case 3. The policy moves everyone's wealth closer to the mean, whereas whether the wealth of the median person is greater than or less than $I$ determines whether there is a high- or a low-wage equilibrium. Starting from a low-wage equilibrium, if the mean is greater than $I$, then such a redistributive policy will push the economy towards a high-wage equilibrium. Even if the mean is less than $I$ in which case the high-wage equilibrium cannot be achieved, the policy will increase the number of enterprises that are operated and hence raise total income. Similarly, in Case 2 such a policy will increase the number of enterprises that are operated and hence, raise total income.

However, the implication of this exercise is not to support any egalitarian redistributive policy to increase total income, rather only those that increase the number of enterprises 
operating in the economy. For example, in Case 3, if the mean wealth level is less than $I$, then a complete redistribution will push the economy to subsistence.

\section{Extension: stochastic model with mobility}

An important feature of the model in Section 2 is that the incomes of all agents, and the bequests of their progeny are all deterministic. This is unsatisfactory as the long-run wealth distribution has all probability mass concentrated on two points (for a low-wage equilibrium) or one point (the high-wage equilibrium or the subsistence equilibrium). As a result, there is no mobility across classes. In this section, we examine the implications of allowing upward and downward mobility through random shocks.

In particular, we assume that every individual's saving rate is subject to an idiosyncratic i.i.d. shock. In every period, each individual's saving rate could be high $(\bar{s})$ with probability $p$ or low $(s)$ with probability $1-p .^{10}$ If $\bar{s}(s)$ is high (low) enough, we will have upward (downward) mobility which is absent in the stationary distributions discussed in Section 2. ${ }^{11}$

We make the following assumptions about the parameters $\underline{s}$ and $\overline{\mathrm{s}}$ :

\section{Assumption 3}

$$
\bar{s}>\frac{I}{\underline{w}+r I} \text { and } \underline{s}=0
$$

The first part of the equation of Assumption 3 ensures there is upward mobility in this economy. Notice that $I /(\underline{w}+r I)<\bar{s}$ implies there exists an integer $m$ such that

$$
m=\min \left\{n \in N: \bar{s}\left[\sum_{i=0}^{n-1}(r \bar{s})^{i} \underline{w}\right] \geq I\right\} .
$$

That is, it takes at most $m$ consecutive periods of good luck for a dynasty-even if it started with no initial wealth and even if wage rates remained low-to become rich.

The second part of the assumption, of course, ensures there is downward mobility in this economy, but more importantly, it greatly simplifies the analysis. By setting $\underline{s}=0$, an individual dynasty's wealth dynamics depends on the history only up to the last time it received a bad shock. Together with the first part, Assumption 3 implies the fraction of the poor, and therefore the current wage rate depends on the wage dynamics only up to the previous $m$ periods. Together with the fact that the wage rate can only be high or low, this implies that the resulting wage dynamics must be either one of the following three types: always high wage, always low wage, or a cycle.

10 These shocks could be taste shocks or shocks related to the technology of saving (e.g., a negative shock could be interpreted as an individual's savings being stolen or expropriated).

11 An alternative way to introduce random shocks in the model would be to let production be stochastic (as in Banerjee and Newman, 1993). However, given our assumptions about the production technology and preferences, the contractual form of payment to workers will be indeterminate (for example, wage contracts or profit/output sharing contracts will be equivalent). This is unsatisfactory since the specific contractual form will be crucial in driving the extent of upward and downward mobility in the model. 
To be more specific, given date $t$, we can define function $a_{t}(\cdot):\{0,1, \ldots, t\} \rightarrow R_{+}$as

$$
\begin{aligned}
& a_{t}(0)=0 \\
& a_{t}(n)=\bar{s}\left[\sum_{i=0}^{n-1}(r \bar{s})^{i} w_{t-i-1}\right] \quad \text { if } n \in\{1, \ldots, t\} .
\end{aligned}
$$

Therefore, $a_{t}(n)$ represents the initial wealth level at date $t$ of a dynasty which received exactly $n$ consecutive periods of good luck and was a wage-earner during these $n$ periods. The distribution that $a_{t}(n)$ describes differs from the real wealth distribution at date $t$ since wealthy people could be earning entrepreneurial profits instead of wages. However, for dynasties that were wage earners, $a_{t}(n)$ correctly represents their initial wealth levels at date $t$. Therefore, at date $t(\geq m)$, there will be a probability mass $p^{n}(1-p)$ at $a_{t}(n), \forall n=0$, $1, \ldots, l(t)$, where $l(t)=\min \left\{n: a_{t}(n) \geq I\right\}$. Since there is no poor dynasty whose wealth level is different from $a_{t}(n), \forall n=0,1, \ldots, l(t)-1$,

$$
G_{t}(I)=\sum_{n=0}^{l(t)-1} p^{n}(1-p) .
$$

Because $l(t) \leq m, \forall t, G_{t}(I)$ depends on at most $\left\{w_{t-i-1}\right\}_{i=0}^{m-1}$. Without loss of generality, we can use a function $f: W^{m} \rightarrow W$, where $W=\{\underline{w}, \bar{w}\}$, to describe the relationship between current wage rate and the wage rates in the previous $m$ periods. Two results follow immediately:

Lemma 2. The wage dynamics can be either stationary (with high or low wages), or display cycles.

Proof: See Appendix A.

Lemma 3. $f$ is weakly increasing in each of its elements.

Proof: See Appendix A. We divide our discussion for the rest of this section into two cases, constant-wage dynamics and cycles.

\subsection{Constant-wage dynamics}

In the following proposition, we show that if $\bar{s}$ is not too large, the stationary wage dynamics can only be of two types: always high wage or always low wage.

Proposition 4: In addition to Assumption 3, if $\bar{s} \leq 1 / r$, then the stationary wage dynamics can only be either always high wage or always low wage.

Proof: See Appendix A.

Which case will emerge depends on how fast the poor become rich when wages are high or low, and in some cases, the initial wealth distribution. This characterization is provided by Proposition 5. If $r \bar{s} \leq 1$, in the expression for the wealth level of a currently poor dynasty, wage rates in the recent past receive greater weight than wage rates in the distant past. From the proof of Proposition 4 , if $w_{t}=\bar{w}$, the wealth distribution of the poor 
is going to remain the same or shifts to the right (first-order stochastic dominance), and in either case, $w_{t+1}=\bar{w}$. If $w_{t}=\underline{w}$, the opposite happens. The wealth distribution at date $t+1$ is the same as the wealth distribution at date $t$, or is first-order stochastically dominated by it and hence, $w_{t+1}=\underline{w}$.

Next, we ask under what conditions the economy will converge to the high-wage equilibrium. Intuitively, if the chance of receiving a high-saving shock is high ( $p$ large) and if it does not take long for a very poor dynasty to become rich ( $m$ small), the economy should end up with a high-wage equilibrium. On the other hand, the low-wage equilibrium would emerge if the chance of an individual to be born with no wealth is high ( $p$ small) and if it takes many periods to become rich. Between these two extremes, there should be cases where the initial distribution matters. We formally prove this in Lemma 4 and Proposition 5. Let us first define $m^{\prime}$, similar to $m$, as the number of periods needed for a zero-wealth dynasty to become rich under high wages. In other words,

$$
m^{\prime}=\min \left\{n \in N: \bar{s}\left[\sum_{i=0}^{n-1}(r \bar{s})^{i} \bar{w}\right] \geq I\right\}
$$

Naturally, $m^{\prime} \leq m$.

Lemma 4. If $p^{m} \geq 1 / 2$, then the economy converges to the high-wage equilibrium. If $p^{m^{\prime}}<1 / 2$, then the economy converge to the low-wage equilibrium.

\section{Proof: See Appendix A.}

Given Lemma 4, we can prove the following proposition:

Proposition 5: The initial distribution of wealth matters in determining the stationary distribution of wealth and the long-run equilibrium wage rate in the stochastic model if and only if

$$
p^{m^{\prime}} \geq \frac{1}{2}>p^{m}
$$

Otherwise the economy converges to a high-wage equilibrium (if $p^{m^{\prime}} \geq p^{m}>1 / 2$ ) or a lowwage equilibrium (if $1 / 2>p^{m^{\prime}} \geq p^{m}$ ) irrespective of initial conditions.

Proof: See Appendix A.

In the case where the initial wealth distribution can matter, it is difficult to give conditions on initial distributions under which the economy would end up with a high- or low-wage equilibrium. Intuitively, if the economy starts out with many rich people, the high-wage rate would be likely to last for many periods. As a result, by the time most of those who were originally rich would be hit by a low savings shock, some of those who were originally poor would accumulate enough wealth. Therefore, the stationary distribution is more likely to be the one associated with the high wage. Conversely, if the economy starts out with many poor individuals, the low-wage rate would last for a long time. Then only a few lucky individuals will be able to accumulate enough wealth 


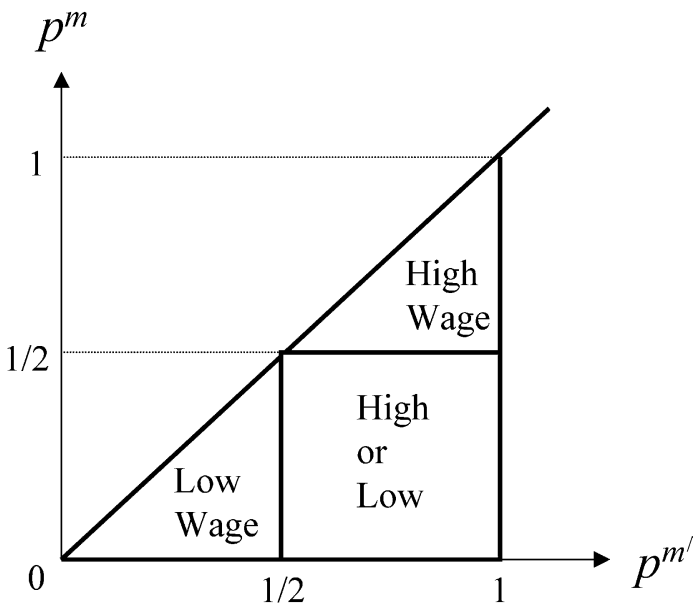

Fig. 3. Long-run wage rates under different parameter configurations (Stochastic Model).

before being hit by a low savings shock. Therefore, the low-wage equilibrium would result.

Proposition 5 provides conditions on parameters under which multiple stationary distributions may exist (also see Fig. 3). Other things being the same, the greater is the difference between the productivity of the modern and the subsistence technology (namely, $\bar{w}$ and $\underline{w}$ ), the greater will be the difference between $m$ and $m^{\prime}$, and the more likely this case will occur. Also, this case is more likely with intermediate values of $I$. The higher (lower) is $I$ the higher (lower) will be both $m$ and $m^{\prime}$ and for given $p$ the more likely the economy will end up in a low (high) wage equilibrium.

Since the number of firms operating in a low-wage equilibrium $\left(p^{m}\right)$ is less than that under a high-wage equilibrium for parameter values for which initial conditions matter, the greater is the fraction of the population who are initially poor, the more likely the economy will end up in a low-wage equilibrium with a lower level of long run per capita income. This is similar in spirit to Proposition 3 in the nonstochastic model. However, in the lowwage equilibrium of the nonstochastic model, the long-run number of firms depends on the parameters of the model as well as the initial fraction of poor individuals, whereas in the stochastic model it depends only on the parameters.

\subsection{Cycles}

From Proposition 4 and Lemma 3, if $\bar{s}$ is large enough $(s>1 / r)$ and if $p^{m^{\prime}} \geq 1 / 2>p^{m}$, the economy does not necessarily converge to a constant-wage equilibrium; the wage dynamics might display cycles. ${ }^{12}$ It is difficult to provide general results for this case

\footnotetext{
12 It turns out that we do not need $\bar{s} \leq 1 / r$ to prove Lemma 4 and Proposition 5 . In other words, they are true even when $s>1 / r$.
} 
and we restrict our discussion around a simple example of a cycle, the simplest one we can find, where the high wage and the low wage alternate with each other.

Example: Suppose $\bar{s}>1 / r, m=3, m^{\prime}=2$, and $p^{2} \geq 1 / 2>p^{3}$. If $\bar{s}[(r \bar{s}) \underline{w}+\bar{w}]<I \leq \bar{s}[(r \bar{s}) \bar{w}+\underline{w}]$, then the wage dynamics might display a two-period cycle where high wage and low wage alternate with each other. $^{13}$

Starting with a high-wage period $w_{t}=\bar{w}$, the wealth distribution must display a probability mass

(i) $(1-p)$ at $a=0$ consisting of those who received a bad saving shock last period;

(ii) $p(1-p)$ at $a=\bar{s} \underline{w}$ consisting of those who received a bad saving shock in the period before last period, but a good shock in the last period (notice that the wage rate in the previous period was low);

(iii) $p^{2}(1-p)$ at $a=\bar{S}[(r \bar{s}) \bar{w}+\underline{w}]$, consisting of those who received a good saving shock in the last two periods (notice that the wage rate in the period before the previous period was high);

(iv) $p^{3}$ consisting of those with $a>\bar{s}[(r \bar{s}) \bar{w}+\underline{w}]$.

Since $\bar{s}[(r \bar{s}) \bar{w}+\underline{w}] \geq I$, and, by assumption $w_{t}=\bar{w}$ in the current period, the fraction of the poor cannot be more than half. This is indeed the case as $1-p^{2} \leq 1 / 2<1-p^{3}$. In the next period, the wealth distribution has a probability mass $(1-p)$ at $0, p(1-p)$ at $\bar{s} \bar{w}$, and $p^{2}(1-p)$ at $\bar{s}[(r \bar{s}) \underline{w}+\bar{w}]$, and $p^{3}$ consisting of those with $a>\bar{s}[(r \bar{s}) \underline{w}+\bar{w}]$. Again, since $1-p^{2} \leq 1 / 2<1-p^{3}$ and $\bar{s}[(r \bar{s}) \underline{w}+\bar{w}]<I$ the wage rate drops back to $\underline{w}$. In period $t+2$, the wealth distribution changes back to that of period $t$ which results in a high-wage rate and the same process goes on forever.

Cycles in our model can occur in the special case when the positive savings shock is very high — so high that a dynasty that receives only positive saving shocks will become infinitely rich just by saving, however small the initial amount it started off with. Then current wages will have a large impact on future income. When wages are high the richest among the poor stay poor because past wages (which are low) play a dominant role. Since there is only downward mobility but no upward mobility, the wage rate switches from high to low. But then, even though the wage is low, the richest dynasties among the poor become rich since the high wage they experienced previously is weighted by $(\bar{s} r)^{2}$. The parameter configuration we assume ensures that there is more upward mobility than downward mobility so that the wage rate becomes high again. This process will go on forever and the economy will display cycles. Aghion et al. (1999) also show the possibility of endogenous cycles in a model with imperfect credit markets, but the mechanism there is very different. In their model, high investment generates high future profits and investment, but it also pushes up the interest rate, which reduces future profits and investment. If the second effect is strong enough relative to the first, output will display negative serial correlation.

\footnotetext{
13 This is not the only possible outcome. Depending on the initial distribution we could also get a stationary equilibrium with low or high wages.
} 


\section{Conclusion}

In this paper, we analyzed a simple dynamic model of occupational choice in the presence of credit market imperfections where wealth inequality and returns to various occupations are endogenous. We examined conditions under which multiple steady-state equilibria exist and characterized how initial conditions affect which equilibrium the economy converges to. We conclude with two observations both of which suggest directions for future research. First, there are many interesting questions regarding the relationship between credit market imperfections and economic development that the current model or models similar to it (such as Banerjee and Newman, 1993, on which it is based, and also Galor and Zeira, 1993; Piketty, 1997) cannot address. As examples, one can mention recent research studying consequences of dynastic utility maximization in a similar framework and a richer set of possible occupations (see Mookherjee and Ray, 2000), allowing entrepreneurs to have heterogeneous talent (Bernhardt and Lloyd-Ellis, 2000), and the interaction between credit market imperfections and incentives and contracting in the labor market (see Ghatak et al., 2001). Second, while there is some cross-country evidence on the negative effect on inequality and measures of credit market imperfections on growth (Benabou, 1996) that is consistent with the prediction of this model, more micro-level evidence on the effect of borrowing constraints on economic mobility is clearly needed. ${ }^{14}$

\section{Acknowledgements}

We thank the anonymous referees for helpful comments, and Christian Ahlin, Abhijit V. Banerjee, Charles Hunter, Joseph Kabowski, Alexander Karaivanov, and Andreas Lehnert for useful discussions. We are responsible for all remaining errors.

\section{Appendix A}

Proof of Lemma 2: First, for any $\mathbf{w}=\left(w_{1}, w_{2}, \cdots, w_{m}\right) \in W^{m}$, we can define a function $M: W^{m} \rightarrow W^{m}$ as

$$
M(\mathbf{w})=\left(w_{2}, w_{3}, \cdots, w_{m}, f(\mathbf{w})\right)
$$

Second, we compare $\mathbf{w}$ with $M(\mathbf{w})$ : if $\mathbf{w}=M(\mathbf{w})$, we stop. If $\mathbf{w} \neq M(\mathbf{w})$, then we calculate $M^{2}(\mathbf{w}) \equiv M(M(\mathbf{w}))$ and check if it is equal to either $\mathbf{w}$ or $M(\mathbf{w})$. If yes, we stop; if no, then we compare $M^{3}(\mathbf{w})$ with $\mathbf{w}, M(\mathbf{w})$, and $M^{2}(\mathbf{w})$, and so on. Since wage rate $w$ only takes two

\footnotetext{
14 There has been some work on this area using panel data sets from the US and the UK (see, for example Evans and Leighton, 1989; Blanchflower and Oswald, 1998). But very little is known about developing countries where borrowing constraints are presumably much more severe.
} 
values $(\underline{w}$ and $\bar{w})$ and $m$ is finite, this process cannot go on forever. There must exist some $k$ and $k^{\prime}$ with $0 \leq k<k^{\prime} \leq 2^{m}-1$ such that $M^{k}(\mathbf{w})=M^{k^{\prime}}(\mathbf{w})$. Third, since $M^{k}(\mathbf{w})=M^{k^{\prime}}(\mathbf{w})$ implies $M^{k+t}(\mathbf{w})=M^{k^{\prime}+t}(\mathbf{w})$ which in turn implies $f\left(M^{k+t}(\mathbf{w})\right)=f\left(M^{(k+t)+\left(k^{\prime}-k\right)}(\mathbf{w})\right)$ for all $t=0,1,2, \ldots$, the wage dynamics displays a $\left(k^{\prime}-k\right)$-period cycle. A special case is when $k^{\prime}-k=1$ where we have constant-wage dynamics.

Proof of Lemma 3: Let $\mathbf{w}, \mathbf{w}^{\prime} \in W^{m}$ and $\mathbf{w} \leq \mathbf{w}^{\prime}$. Then

$$
\begin{aligned}
\bar{s}\left[\sum_{i=0}^{n-1}(r \bar{s})^{i} w_{m-i}\right] & \leq \bar{s}\left[\sum_{i=0}^{n-1}(r \bar{s})^{i} w_{m-i}^{\prime}\right] \quad \text { for } n=1,2, \ldots, m \\
& \Rightarrow a(n) \leq a^{\prime}(n) \quad \text { for } n=1,2, \ldots m \\
& \Rightarrow l \geq l^{\prime} \\
& \Rightarrow \sum_{n=0}^{l-1} p^{n}(1-p) \geq \sum_{n=0}^{l^{\prime}-1} p^{n}(1-p) \\
& \Rightarrow G(I) \geq G^{\prime}(I) \\
& \Rightarrow f(\mathbf{w}) \leq f\left(\mathbf{w}^{\prime}\right)
\end{aligned}
$$

Proof of Proposition 4: For any $t \geq m$, there is a probability mass $p^{n}(1-p)$ at $a_{t}(n)$, $\forall n=0,1, \ldots, l(t)$. Compare $a_{t+1}(n)$ with $a_{t}(n)$,

$$
\begin{aligned}
a_{t+1}(n)-a_{t}(n) & =\bar{s}\left[\sum_{i=0}^{n-1}(r \bar{s})^{i} w_{t-i}\right]-\bar{s}\left[\sum_{i=0}^{n-1}(r \bar{s})^{i} w_{t-i-1}\right] \\
& =\bar{s}\left\{w_{t}-(1-r \bar{s})\left[\sum_{i=0}^{n-2}(r \bar{s})^{i} w_{t-i-1}\right]-(r \bar{s})^{n-1} w_{t-n}\right\} \\
& \in\left[\bar{s}\left(w_{t}-\bar{w}\right), \bar{s}\left(w_{t}-\underline{w}\right)\right] .
\end{aligned}
$$

If $\quad w_{t}=\bar{w}, \quad a_{t+1}(n)-a_{t}(n) \geq 0 . \quad$ This implies $\quad l(t+1) \leq l(t)$ and since $G_{t}(I)=$ $\sum_{i=0}^{l(t)-1} p^{i}(1-p) \leq 1 / 2, G_{t+1}(I)=\sum_{i=0}^{l(t+1)-1} p^{i}(1-p) \leq 1 / 2$. That is, $w_{t+1}=w_{t}=\bar{w}$. If 
$w_{t}=\underline{w}, \quad a_{t+1}(n)-a_{t}(n) \leq 0 . \quad$ This implies $l(t+1) \geq l(t)$ and since $G_{t}(I)=\sum_{i=0}^{l(t)-1} p^{i}(1-p)>$ $1 / 2, G_{t+1}(I)=\sum_{i=0}^{l(t+1)-1} p^{i}(1-p)>1 / 2$. That is, $w_{t+1}=w_{t}=\underline{w}$.

Proof of Lemma 4: If $p^{m} \geq 1 / 2$, then $\sum_{i=0}^{m-1} p^{i}(1-p) \leq 1 / 2$, which in turn implies that $f(\underline{w}$, $\underline{w}, \ldots, w)=\bar{w}$. Therefore, from Lemma $3, f(\cdot)=\bar{w}$ for any element in $W^{m}$. If $p^{m^{\prime}}<1 / 2$ then $\sum_{i=0}^{m^{\prime}-\Gamma} p^{i}(1-p)>1 / 2$ which in turn implies that $f(\bar{w}, \bar{w}, \ldots, \bar{w})=\underline{w}$. Therefore, from Lemma $3, f(\cdot)=\underline{w}$ for any element in $W^{m}$.

Proof of Proposition 5: The "only if" part is implied by the previous Lemma. To prove the "if" part, it suffices to find two wealth distributions such that one is consistent with the high-wage equilibrium, whereas the other is consistent with the low-wage equilibrium. The obvious choice for such a distribution is one in the steady state. First, for the highwage equilibrium, consider a wealth distribution at date $t$ that has a probability mass

$$
\begin{array}{ccc}
(1-p) & \text { at } & 0 \\
p^{n}(1-p) & \text { at } \quad \bar{s}\left[\sum_{i=0}^{n-1}(r \bar{s}) \bar{w}\right] \quad \forall n=1,2, \ldots
\end{array}
$$

From the definition of $m^{\prime}$, we know

$$
\bar{s}\left[\sum_{i=0}^{m^{\prime}-1}(r \bar{s}) \bar{w}\right]<I \leq \bar{s}\left[\sum_{i=0}^{m^{\prime}}(r \bar{s}) \bar{w}\right]
$$

and therefore

$$
G_{t}(I)=\sum_{n=0}^{m^{\prime}-1} p^{n}(1-p)=1-p^{m^{\prime}} \leq \frac{1}{2}
$$

This implies $w_{t}=\bar{w}$ which in turn implies the next-period wealth distribution remains exactly the same. By changing $m^{\prime}, \bar{w}$ to $m, \underline{w}$, one can show that the low-wage equilibrium may also emerge in a similar way. The only difference is that the wealth distribution similarly constructed is not the steady-state distribution since the rich can earn entrepreneurial profits instead of wages. But since it is the wealth transition of the poor that matters in determining the wage rate, the argument is still valid.

\section{References}

Aghion, P., Bolton, P., 1997. A trickle-down theory of growth and development with debt overhang. Review of Economic Studies 64 (2), 151-172.

Aghion, P., Banerjee, A., Piketty, T., 1999. Dualism and macroeconomic volatility. Quarterly Journal of Economics 114 (4), 1359-1398. 
Banerjee, A.V., Newman, A., 1993. Occupational choice and the process of development. Journal of Political Economy 101 (2), 274-298.

Banerjee, A.V., Newman, A., 1994. Poverty, incentives, and development. American Economic Review Papers and Proceedings 84 (2), 211-215.

Barro, R., Sala-i-Martin, X., 1995. Economic Growth. McGraw-Hill, New York.

Benabou, R., 1996. Inequality and growth. In: Bernanke, B.S., Rotemberg, J.J. (Eds.), NBER Macroeconomic Annual, 1996. MIT Press, Cambridge, pp. 11-74.

Bernhardt, D., Lloyd-Ellis, H., 2000. Enterprise, inequality and economic development. Review of Economic Studies 67 (1), 147-168.

Blanchflower, D.G., Oswald, A.J., 1998. What makes an entrepreneur? Journal of Labor Economics 16 (1), $26-60$.

Evans, D., Leighton, L., 1989. Some empirical aspects about entrepreneurship. American Economic Review 79 (3), 519-535.

Galor, O., Zeira, J., 1993. Income distribution and macroeconomics. Review of Economic Studies 60 (1), $35-52$.

Ghatak, M., Morelli, M., Sjöström, T., 2001. Occupational choice and dynamic incentives. Review of Economic Studies 68 (4), $781-810$.

Mookherjee, D., Ray, D., 2000. Persistent inequality. Institute for Economic Development Discussion Paper \#108, Boston University.

Piketty, T., 1997. The dynamics of wealth distribution and the interest rate with credit rationing. Review of Economic Studies 64 (2), 173-189. 